\title{
Zebra Hunting: How Caring Is Lost When We Chase Diseases
}

Lao-Tzu Allan-Blitz, MD ${ }^{1,2}$ (1)

'Division of Global Health Equity: Department of Medicine, Brigham and Women's Hospital, Boston, MA, USA; ${ }^{2}$ Department of Medicine, Boston Children's Hospital, Boston, MA, USA.

J Gen Intern Med 36(9):2816-7

DOI: $10.1007 / \mathrm{s} 11606-020-06268-1$

(c) Society of General Internal Medicine 2020

$W$ hen you hear hoofbeats, think horses not zebras-so the old adage goes, but if you were an intern like me, medicine was all about the zebras. For the most part, case presentations in the hospital start and end the same way: a vague one-liner, a few precious tidbits of data, and then our differential diagnosis. I have yet to be in a case conference where the first thing suggested is the most common cause of the complaint. Instead, we indulge in the opportunity to show just how esoteric we can be: it could be ...-insert any plausible condition unlikely to be on the minds of those around you and you score points. And invariably, at the end, the diagnosis is some obscure and extremely rare creature with black-and-white stripes (Scimitar syndrome, Naegleria fowleri infection, etc.).

On the wards, it's not much different. My last differential was filled with conditions I secretly hoped it might be - the "interesting" cases. Sometimes, when the diagnosis is too obvious to ignore, I dive into the improbable causes of that "uninteresting" disease. Our elderly woman with two previous heart attacks who is now in heart failure might be so because of the cumulative effect of ischemia on her poor myocardium, or it could be an exceedingly rare invasion of the myocardium by a previously undiagnosed $\mathrm{T}$ cell acute lymphoblastic leukemia, because it could always be, but never really is.

A part of that chase is driven by my own fear, my own selfdoubt: would I be able to summon that diagnosis when push comes to shove and I'm on my own? So, I look for them everywhere. But we're also empowered to think that way. Despite the wise adages, we are constantly presented cases, lectures, and journal articles of the rare and atypical. It's a part of our education system and how we practice medicine. If we don't send the test, we may miss one of those zebras prancing around right under our noses. And so, in hyper-resourced institutions, as long as it doesn't cause harm, we do. We send expensive work-ups and specialty blood tests literally across

Received August 25, 2020

Accepted September 21, 2020

Published online October 1, 2020 the country to the only laboratory where they can be run. It's not for no reason either; thrillingly, every now and then one of those tests comes back positive.

It never bothered me, that inspired chase for "interesting" cases, the hunt for zebras, until I was in Malawi. Rounding on the male medical ward - a room the size of a basketball court with high windows, spiders crawling on the off-white walls, and 20 beds - we met a somnolent elderly gentleman who had just been put on oxygen. He was frail, thin, and looked sick - the kind that catches your eye when you walk into a room. We were told he had presented the day before with what was diagnosed as a new psychotic episode, was given Seroquel, and had fallen asleep. The nurse then found him in a stupor that morning, tachypneic and hypoxic to the mid-80s. He was in respiratory distress, using accessory muscles to breathe. His lung sounds were asymmetric with crackles and reduced air movement on the left side. The tests available to us included a complete blood count, general chemistries, liver function tests, and a chest X-ray. We ordered all of them. We started him on ceftriaxone and azithromycin for presumed pneumosepsis and gave intravenous fluids. We then waited for our tests to come back. My thoughts raced past the obvious. Could it be an exotic infection? Tuberculosis? Visceral Leishmaniasis? Neurocysticercosis? Or some strange inflammatory syndrome? On and on.

His blood count returned the following morning with only mild anemia, but the chemistry and liver function tests could not be run because the lab was missing the required cartridges. The chest X-ray had not been performed, but his oxygen requirement had increased. The question of what is the most likely diagnosis? was suddenly dichotomized. We needed to treat what was likely enough to warrant utilization of precious resources, while at the same time aware that if the cause of his symptoms was truly a zebra, there wouldn't be much we could offer. So, did it really matter if we got an answer? It was as if the primary question in my mind changed: what can we do to help him? Are we doing everything we can to give him the best chance of recovery in the face of uncertainty?

I walked out of the hospital in the late afternoon, the sky a type of blue that we don't see very often in the United States, the red dirt still drying from the rain. The trees were bright and green, and if it hadn't been for the thoughts in my head it would have been a beautiful walk back to the guesthouse. I was surprised to find myself thinking of my mom. When she was diagnosed with a fourth recurrence of metastatic breast 
cancer, she asked my brothers and me if we would be okay with her ending her own life if and when things became too difficult for her. Over fifteen years she had tried every avenue of treatment (classic and alternative) and every type of palliation. In the end, she passed away with us surrounding her, reminding her how loved she was. She wanted to die with dignity, and it was the best thing we could have done to help her.

Lying on my bed under the mosquito net, the fan whirring behind the occasional sounds from outside, I realized how little I cared about her diagnosis in the end. What mattered was what we could do for her. I thought of the man in the male medical ward and about the light from the illuminator flickering on and off as we read the chest X-ray. I remembered my relief seeing the large lobar pneumonia; our treatment will work, I thought. I was strangely much more satisfied with our "uninteresting" diagnosis than if it had been a zebra, because now I was confident we could help him. Sometimes, I realized, the diagnosis isn't all that important so long as we're able to help.

A few months later, after SARS-CoV-2 stormed across the globe, standing in our county hospital nervously pulling a second pair of gloves over my already gloved hands, my breath fogging my face shield, I was again reminded of the man in the male medical ward in Malawi. There were no zebras to chase. What mattered to my isolated and recovering patient were the few brief minutes in the day that he was able to talk with someone face to masked-face, the frequent calls to his room in the afternoon to check in on him, the occasional Facetime call from his son or daughter.
I and other zebra hunters like me may always be fascinated by the rare cases of the world, and I don't think that's a fault. But maybe chasing zebras can at times damage the care we provide to our patients by making the disease more interesting to us than the person in the bed. That, I think, is at least worth thinking about the next time we hear hoofbeats.

Corresponding Author: Lao-Tzu Allan-Blitz, MD; Division of Global Health Equity: Department of Medicine, Brigham and Women's Hospital, Boston, MA, USA (e-mail: lao.allanblitz@gmail.com).

\section{Compliance with Ethical Standards:}

The manuscript has been reviewed by the healthcare providers mentioned herein, all of whom have given permission for publication. We were not, however, able to reach the patient described in Malawi as he was lost to follow-up-no patient identifying information has been documented.

Conflict of Interest: The author declares that he/she does not have a conflict of interest.

Publisher's Note: Springer Nature remains neutral with regard to jurisdictional claims in published maps and institutional affiliations. 